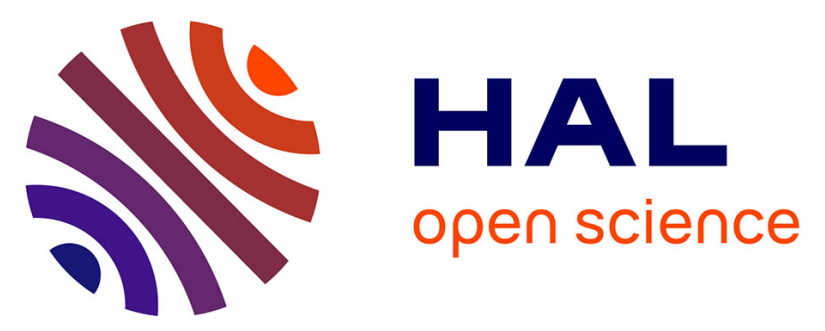

\title{
Multi-technique study of precipitation in the nearfusion boundary region of an aged narrow-gap dissimilar metal weld
}

\author{
Frédéric de Geuser, A Akhatova, Frederic Danoix, F Robaut, M Yescas, F \\ Roch, C Tassin, Hugo P. van Landeghem
}

\section{To cite this version:}

Frédéric de Geuser, A Akhatova, Frederic Danoix, F Robaut, M Yescas, et al.. Multi-technique study of precipitation in the nearfusion boundary region of an aged narrow-gap dissimilar metal weld. Materialia, 2021, 16, 10.1016/j.mtla.2021.101106 . hal-03216542

\section{HAL Id: hal-03216542 \\ https://hal.science/hal-03216542}

Submitted on 4 May 2021

HAL is a multi-disciplinary open access archive for the deposit and dissemination of scientific research documents, whether they are published or not. The documents may come from teaching and research institutions in France or abroad, or from public or private research centers.
L'archive ouverte pluridisciplinaire HAL, est destinée au dépôt et à la diffusion de documents scientifiques de niveau recherche, publiés ou non, émanant des établissements d'enseignement et de recherche français ou étrangers, des laboratoires publics ou privés. 


\title{
Multi-technique study of precipitation in the near- fusion boundary region of an aged narrow-gap dissimilar metal weld
}

\author{
F. De Geuser ${ }^{\mathrm{a}}$, A. Akhatova ${ }^{\mathrm{a}}$, F. Danoix ${ }^{\mathrm{b}}$, F. Robaut ${ }^{\mathrm{a}}$, M. Yescas $^{\mathrm{c}}$, F. Roch ${ }^{\mathrm{c}}$, C.Tassin ${ }^{\mathrm{a}}$, H.P. Van \\ Landeghem, ${ }^{\mathrm{a}, *}$ \\ a Univ. Grenoble Alpes, CNRS, Grenoble INP, SIMAP, F-38000 Grenoble, France \\ b Normandie Univ., UNIROUEN, INSA Rouen, CNRS, Groupe de Physique des Matériaux, 76000 \\ Rouen, France \\ ${ }^{c}$ Framatome, Materials, Chemistry \& Technology Department, 1 Place Jean Millier, 92084 Paris La \\ Défense CEDEX, France
}

\begin{abstract}
In ferrite/austenite dissimilar metal welds, carbon can diffuse from the ferritic low-alloy steel to the austenitic weld metal during heat treatment and thermal aging due to the large carbon and chromium content differences between the two alloys. This carbon influx leads to the precipitation of carbides in the high-alloy weld metal, near the fusion boundary, which can affect the properties of the joint. This precipitation was investigated using multiple characterization techniques: electron probe microanalysis, small angle X-ray scattering and atom probe tomography. The studied joint consisted of low-alloy steel and stainless steel base metals that were arc welded using a nickel-based filler metal. Given the heterogeneous microstructure of such joints, a microstructure navigation strategy was implemented to ensure all characterizations were carried out in the same regions of interest and the associated data could later be correlated. The precipitates were found to be mostly $\mathrm{M}_{23} \mathrm{C}_{6}$. The precipitation was quantified using two different methods that gave comparable results, whose differences highlight the capabilities and limitations of each technique. Precipitate fractions are higher following thermal aging but remain far from equilibrium in all cases, indicating that precipitation kinetics should be accounted for to model the microstructural evolution of such dissimilar metal welds more accurately.
\end{abstract}

Keywords: Dissimilar Metal Weld, Gas Tungsten Arc Welding, Precipitation, Electron Probe Microanalysis, Atom Probe Tomography, Small Angle X-ray Scattering.

\section{Introduction}

In nuclear power plants, the pursuit of efficiency and safety at reasonable costs results in the usage of a variety of metallic alloys across the components of the system, based on their properties. In particular, large components like the reactor pressure vessel are made of a bainitic low-alloy steel (LAS) and must be joined to the primary coolant pipes made of austenitic stainless steel (ASS). These dissimilar metal welds (DMWs) are achieved using gas tungsten arc welding (GTAW). In primary water environments, modern designs usually rely on a face centered cubic (FCC) nickel-based alloy as filler metal. At the LAS fusion boundary, the composition changes abruptly from the LAS composition to the one of the weld metal and the structure changes from body centered cubic (BCC) to FCC. This composition gradient, in particular the chromium content gradient, and the structural change lead to a chemical potential gradient for carbon. These DMWs must withstand service conditions in the $300-350^{\circ} \mathrm{C}$

\footnotetext{
${ }^{*}$ Corresponding author at SIMaP, 1130 rue de la piscine, BP75, 38402 Saint Martin d'Hères Cedex, France. Email : hugo.van-landeghem@grenoble-inp.fr
} 
temperature range. At these temperatures, carbon can diffuse along the existing potential gradient leading to an evolution of the properties of the joint. Consequently, DMWs are regarded as critical points where control of both the microstructure and its evolution are key targets.

The present study focuses on DMWs between 18MND5 and Z2CND18-12 using alloy 52 as a filler metal, as used in Framatome's EPR. This high-chromium filler metal is selected here for its enhanced primary water stress corrosion cracking (PWSCC) resistance. The narrow-gap (NG) geometry studied here does not involve initial buttering of the LAS component, as is commonly the case in traditional wide gap DMWs. Post-weld heat-treatment (PWHT) near $600^{\circ} \mathrm{C}$ is thus applied to the whole DMW. In service, those joints are exposed to temperatures in the $300-350^{\circ} \mathrm{C}$ range for decades.

Given the carbon chemical potential gradient mentioned above, exposure of the DMWs to temperatures where carbon has non-negligible mobility, which is the case for both PWHT and service conditions, results in carbon migration. This migration of carbon leads to a number of microstructural changes that can be summarized as follow. On the LAS side, carbides dissolve and a carbon-depleted zone forms in the region adjacent to the fusion boundary, over a few hundreds of microns [1,2]. In the nickel-based weld metal, the low diffusivity of carbon and its precipitation in Cr-rich carbides [3,4] results in its accumulation close to the fusion boundary over only a few tens of microns. This redistribution of carbon in the microstructure leads to associated changes in mechanical properties, locally in the affected regions but also for the whole joint. Accordingly, many authors have reported an increase in the micro-hardness in weld metal next to the fusion boundary [5-10], which is related to this carbon migration. The magnitude of carbon transport during aging in service conditions was investigated in the present weld and was shown to be strongly correlated to changes in the local mechanical properties [2].

In previous studies, it was observed that Cr-rich precipitates formed and coarsened in the fusion boundary region. The precipitates were identified as $\mathrm{Cr}_{23} \mathrm{C}_{6}$ based upon their TEM diffraction patterns [6,11-13]. Choi et al. [14] studied the Cr-rich precipitates in the fusion boundary region between Alloy 152 and A533 Gr. B low-alloy steel by 3D atom probe. They have shown an increase in the Cr content of the fusion boundary matrix with heat treatment at $400^{\circ} \mathrm{C}$ and $450^{\circ} \mathrm{C}$, which led to additional formation and coarsening of Cr-rich precipitates. Wang et al. [15] characterized the crystal structures of $\mathrm{Cr}_{23} \mathrm{C}_{6}$ carbides and alloy 52M weld metal and found that both precipitate and matrix have FCC crystal structure, and that the lattice constant of $\mathrm{Cr}_{23} \mathrm{C}_{6}$ is 3 times the size of that of alloy $52 \mathrm{M}$, in agreement with prior investigations on the crystal structure of $\mathrm{Cr}_{23} \mathrm{C}_{6}$ [16]. The presence of chromium-rich carbide precipitates isostructural to $\mathrm{Cr}_{23} \mathrm{C}_{6}$ was qualitatively demonstrated in the present DMW [2].

Due to the pronounced effect of carbide precipitation on mechanical properties, it is desirable to understand the kinetics of the different phenomena involved in the precipitation sequence in nuclear power plant DMWs. The various factors that govern the long range carbon transfer during thermal aging have already been examined [2]. The aim of this work is now to investigate the effect of thermal aging on the formation and growth of Cr-rich precipitates in the fusion boundary region between 18MND5 low alloy steel and Inconel $52 \mathrm{Ni}$-based weld metal. However, given the characteristic size of the precipitates with respect to the DMW itself [2], it is challenging to obtain quantitative and representative measurements that are critical to kinetic studies. In order to maximize the relevance and the reliability of the measurements, the present study relies on small angle X-ray scattering (SAXS) in correlation with atom probe tomography (APT) to combine the large-probe, averaged information of the former with the near-atomic resolution of the latter. Data was recorded on samples from a DMW mock-up, after PWHT and following additional thermal aging for up to $50000 \mathrm{~h}$ between $350^{\circ} \mathrm{C}$ and $450^{\circ} \mathrm{C}$. The 
complementarity between the two characterization techniques is discussed before concluding on the precipitation kinetics in the DMW.

\section{Experimental}

\section{A. Materials and processing}

The DMW investigated in this paper is a one-pass-per-layer NG-GTAW weld between a 18MND5 LAS and Z2CND18-12 stainless steel with alloy 52 as filler metal. The chemical compositions of the 18MND5 LAS and the alloy 52 filler metal used for this work are listed in Table 1.

Table 1. Chemical compositions of 18MND5 low-alloy steel, alloy 52 filler metal, and Z2CND18-12 austenitic stainless steel (in wt.\%), as measured by optical emission spectroscopy.

\begin{tabular}{|c|c|c|c|c|c|c|c|c|c|c|c|c|c|c|c|c|}
\hline Materials & $\mathbf{C}$ & $\mathbf{S i}$ & $\mathbf{M n}$ & $\mathbf{P}$ & $\mathbf{S}$ & $\mathbf{N i}$ & $\mathbf{C r}$ & $\mathbf{M o}$ & $\mathbf{C u}$ & $\mathbf{A l}$ & $\mathbf{V}$ & $\mathbf{F e}$ & $\mathbf{T i}$ & $\mathbf{T a}$ & $\mathbf{N b}$ & $\mathbf{N}$ \\
\hline 18MND5 & 0.19 & 0.23 & 1.46 & 0.006 & 0.006 & 0.72 & 0.17 & 0.48 & 0.10 & 0.024 & 0.003 & bal. & - & - & - & - \\
\hline Alloy 52 & 0.026 & 0.13 & 0.25 & 0.004 & 0.001 & bal. & 29.12 & 0.01 & 0.01 & 0.71 & - & 10.1 & 0.51 & 0.003 & 0.01 & - \\
\hline Z2CND18-12 & 0.015 & 0.25 & 1.97 & 0.026 & 0.003 & 11.3 & 16.65 & 2.07 & - & - & - & bal. & 0.005 & - & - & 0.057 \\
\hline
\end{tabular}

To reduce internal residual stresses developed during welding, the mock-up was subjected to PWHT consisting of a total of $16 \mathrm{~h}$ at $610^{\circ} \mathrm{C}$ as detailed in [1]. Subsequent aging treatments were performed in air at temperatures ranging from $350^{\circ} \mathrm{C}$ to $450^{\circ} \mathrm{C}$ for various durations between 5000 and $50000 \mathrm{~h}$ as detailed in Table 2.

Table 2. Isothermal aging conditions

\begin{tabular}{|c|c|c|}
\hline Sample & Temperature, $^{\circ} \mathbf{C}$ & Aging time, $\mathbf{h}$ \\
\hline $\begin{array}{c}\text { PWHT } \\
\text { (initial condition) }\end{array}$ & - & 0 \\
\hline $5 \mathrm{kh} @ 450 \mathrm{C}$ & 450 & 5000 \\
\hline $50 \mathrm{kh} @ 350 \mathrm{C}$ & 350 & 50000 \\
\hline
\end{tabular}

\section{B. Sample preparation}

Samples were cut with the 18MND5 LAS fusion boundary at their center. They were subsequently ground with $\mathrm{SiC}$ abrasive paper down to 4000 grit, followed by polishing using $3 \mu \mathrm{m}$ then $1 \mu \mathrm{m}$ diamond paste. The samples were finished using $0.1 \mu \mathrm{m}$ alumina suspension, thoroughly rinsed with water and further cleaned in ethanol in an ultrasonic cleaner. The ferritic side of the samples was etched using Nital ( $3 \% \mathrm{HNO}_{3}$ in methanol), while the weld side was electrochemically etched in an aqueous chromic acid solution $\left(10 \mathrm{~g} \mathrm{CrO}_{3}\right.$ in $100 \mathrm{ml} \mathrm{H}_{2} \mathrm{O}$ ) under an open-circuit potential of $3 \mathrm{~V}$.

\section{Microstructure navigation for correlative analyses}

Sample microstructures were surveyed using an Olympus BX60M light microscope. About ten regions of interest (ROIs) were pre-selected based on their appearance of the near-fusion boundary microstructure. Those ROIs were marked using micro-indents of various sizes performed with a Wilson Tukon 1102 hardness tester. The general shape of the substitutional composition profiles across the fusion boundary in those areas was then evaluated using energy dispersive spectroscopy (EDS) in a 
Zeiss Gemini scanning electron microscope operated at $15 \mathrm{kV}$. The selection of ROIs was further refined by selecting ROIs with the most similar composition gradients across all samples. For electron probe micro-analyses (EPMA), the measurements must be carried out on flat surfaces [17]. To this end, samples were polished and finished again, thus erasing features revealed by etching. Positioning of the recorded profiles was ensured using hardness micro-indents, which remained visible. Those indents were also used to ensure the positioning of the AP (atom probe) specimens prepared by focused ion beam (FIB) in the ROI.

SAXS analyses required further preparation to ensure measurements in the exact same ROIs. First, SAXS measurements are performed on a foil with appropriate X-ray transmission. To make this foil, the surface used for EPMA and AP experiments was sliced off the samples, about $100 \mu \mathrm{m}$ thick. Two slits were machined on the slice for future use as fiducials as seen in Figure 1. The surface slice was then back ground and back polished down to a thickness of about $30 \mu \mathrm{m}$, to preserve the ROIs characterized by AP and EPMA. During the SAXS experiment, it is not possible to directly visualize where the X-ray beam hits the foil with sufficient precision. This limitation was circumvented by locating the extremities of the fiducials using X-ray transmission measurements. Once these were positioned, the stage could then be moved to the ROIs, whose positions had been recorded relatively to the fiducials. This method ensures reliable and precise positioning, without the need for a specific mounting on the beamline stage. Positioning was checked one last time using X-ray transmission just above the $\mathrm{Cr}$ edge, which varies strongly near the fusion boundary, as detailed below. Ultimately, it was possible to ensure that the measurements from all three techniques were localized close together in the same ROI as depicted in Figure 2.

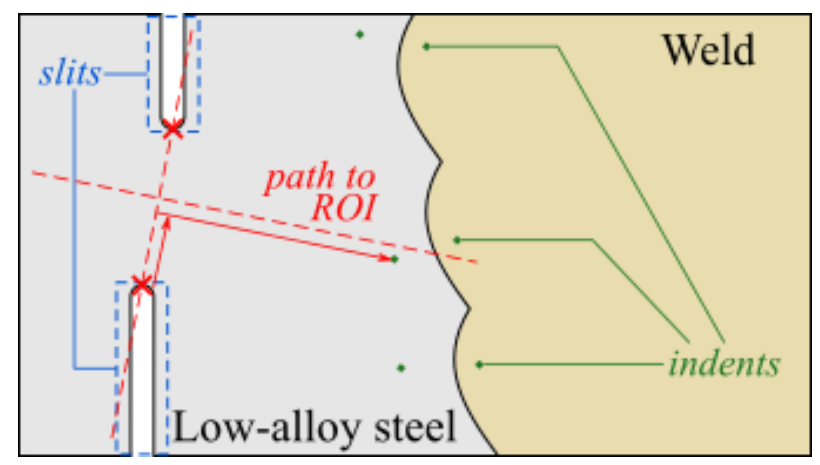

Figure 1: Schematic representation of the specimen used for small angle $X$-ray scattering experiments. The extremities of the slits, marked with red crosses, serve as fiducials to position the $\mathrm{X}$-ray beam in predetermined regions of interest (ROIs) in the absence of direct imaging of the sample, regardless of the sample orientation on the stage.

\section{Electron probe micro-analysis (EPMA)}

Quantitative analysis of $\mathrm{Ni}, \mathrm{Cr}, \mathrm{Mn}$ and $\mathrm{C}$ concentrations across the fusion boundary was carried out by wavelength dispersive spectroscopy (WDS). Analyses were performed using a Cameca SX50 electron probe micro-analyzer, under a $15 \mathrm{kV}$ acceleration voltage, with a $900 \mathrm{nA}$ beam current for $\mathrm{C}$ and $\mathrm{Mn}$ and $150 \mathrm{nA}$ for $\mathrm{Cr}$ and $\mathrm{Ni}$. The count times for peak intensity measurements was $40 \mathrm{~s}$ for $\mathrm{C}$ and $30 \mathrm{~s}$ for metallic elements. The count time for background measurements was $5 \mathrm{~s}$. Measurement step sizes were $20 \mu \mathrm{m}$ in the homogeneous parts of the base and weld metals far from the fusion boundary, and $4 \mu \mathrm{m}$ near the fusion boundary. Quantification was achieved using measurements from pure metal references and the $\phi(\rho z)$ method [18] for correction as implemented in SAMx XMAS software package. The carbon analysis procedure was based on the determination of a calibration curve, as detailed in [19]. 


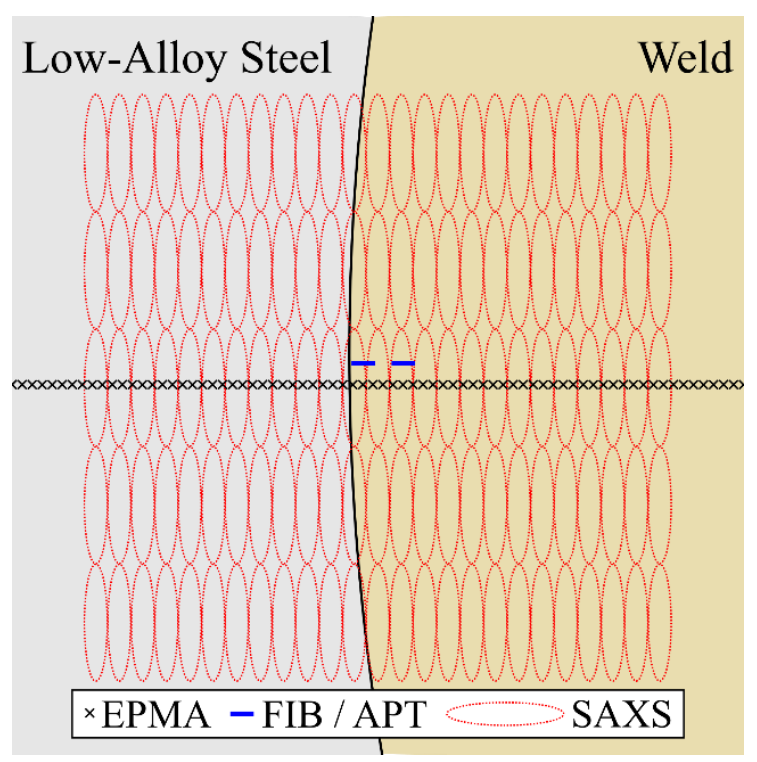

Figure 2: Schematic representation of the locations of the small angle scattering (SAXS), electron probe microanalysis (EPMA) and atom probe tomography (APT) measurements performed in a same region of interest, approximately at scale. The size at the sample of the $X$-ray beam used for small angle scattering was $10 \times 50 \mu \mathrm{m}^{2}$.

\section{E. Atom probe tomography (APT)}

Atom probe experiments were performed with a Cameca LEAP 4000 HR in voltage mode. The atom probe specimens were prepared using the FIB lift-out method in a Thermo Fisher Scientific Helios G4 Xe Plasma FIB Dual Beam microscope [20]. The specimens were taken on a line $10 \mu \mathrm{m}$ away from the EPMA profile and were systematically sharpened past the weld metal surface by at least $100 \mathrm{~nm}$. The pulse fraction and the pulse repetition rate were $20 \%$ and $200 \mathrm{kHz}$, respectively. Analyses were carried out at a base temperature of $50 \mathrm{~K}$, using a $0.5 \%$ detection rate. Data reconstruction was performed using IVAS 3.8.0 (Cameca Instrument).

\section{F. Small angle $X$-ray scattering (SAXS)}

SAXS experiments were performed at the coherent Small-Angle X-ray Scattering (cSAXS) beamline at the Swiss Light Source synchrotron at Paul Scherrer Institut, Villigen, Switzerland. These measurements were aimed at determining the spatial evolution of the volume fraction of the precipitates in the different DMW samples.

The profiles were acquired as maps of 5 lines of 30 points at 6 different energies: - $200 \mathrm{eV},-100 \mathrm{eV}$, $-50 \mathrm{eV},-30 \mathrm{eV},-20 \mathrm{eV}$ and $-10 \mathrm{eV}$ with respect to the $\mathrm{Cr}$ edge $(5.989 \mathrm{keV})$. An additional measurement at $+70 \mathrm{eV}$ above the $\mathrm{Cr}$ edge was used to obtain a high contrast profile allowing precise positioning of the interface given the large $\mathrm{Cr}$ composition difference between 18MND5 (0.17 wt.\%) and the weld metal ( $26 \mathrm{wt} . \%)$. Recording the patterns at different energies was originally planned to leverage the anomalous effect around the Cr-edge to estimate possible precipitate composition variations. However, the presence of bright streaks most likely due to multiple diffraction rendered a significant fraction of the patterns impossible to process and prevented the anomalous analysis. Instead, the spatial redundancy ensured that at least one complete map per ROI would be usable.

The samples were positioned so that the $10 \times 50 \mu \mathrm{m}$ beam would have its major radius parallel to the fusion boundary. This was intended to maximize the spatial resolution of the measurement profiles. The 
sample-to-detector distance was adjusted by using a $2 \mathrm{~m}$ flight-tube, which, given the large Dectris Pilatus 5M hybrid photon counting detector, led to a suitable q-range from 0.006 to $0.16 \AA^{-1}$.

All data collected using X-rays was background corrected and normalized with respect to sample thickness and transmission into absolute units by using a glassy carbon sample as a secondary calibration standard [21]. The local sample thickness was computed through the local energy-dependent transmission (see further).

In order to get the position of fusion boundary relative to the X-ray beam with sufficient accuracy, the local chromium composition is used, which shows a sharp increase across the fusion boundary. The local $\mathrm{Cr}$ content can be probed by comparing the local transmission of the sample below and above the Cr K absorption edge (5.989 keV).

At a given energy $E$, the local transmission can be expressed as:

$$
T_{x}(E)=e^{-\mu_{x}(E) t_{x}}
$$

where $T_{x}$ is the local transmission, and $\mu_{x}$ and $t_{x}$ are the linear absorption coefficient and the thickness of the foil, respectively, at position $x$ on the diffusion couple. For each point on the sample, $T_{x}(E)$ is known for all seven energies. Eq. (1) can be rearranged as:

$$
\mu_{x}=\frac{-\ln \left(T_{x}\right)}{t_{x}}
$$

The sample thickness is independent of the beam energy, while both $\mu_{x}$ and $T_{x}$ depend on the energy $E$. If the transmission measurement is performed at two energies, below and above the absorption edge ( $E_{\text {below }}$ and $E_{\text {above }}$ ), the variation of the local transmission can be used to deduce how the local absorption coefficient $\mu_{x}$ varies at both energies. This variation can then be linked to the local $\mathrm{Cr}$ composition:

$$
\begin{aligned}
& \frac{\mu_{x \_ \text {below }}}{\mu_{x_{\_} \text {above }}}=\frac{\ln \left(T_{x \_ \text {below }}\right)}{\ln \left(T_{x \_ \text {above }}\right)}=A \\
& \frac{\mu_{x_{\_} \text {below }}}{\mu_{x_{-} \text {above }}}=\frac{\left(1-c_{C r}(x)\right) \mu_{C r_{\_} \text {below }}+c_{C r}(x) \mu_{0 \_ \text {below }}}{\left(1-c_{C r}(x)\right) \mu_{C r_{-} \text {above }}+c_{C r}(x) \mu_{0 \_ \text {above }}} \\
& c_{C r}(x)=\frac{\mu_{0 \_ \text {below }}-A(x) \mu_{0 \_ \text {above }}}{\mu_{0 \_ \text {below }}-\mu_{\text {Cr_below }}+A(x)\left(\mu_{\text {Cr_above }}-\mu_{0 \_ \text {above }}\right)}
\end{aligned}
$$

$\mu_{C r}$ and $\mu_{0}$ are the linear absorption coefficients of chromium alone and of all the other elements respectively. An additional equation regarding the local composition is needed to calculate $\mu_{0}$. To this end, a simple rule of mixtures is assumed, i.e. the local composition is taken as the weighted mean of LAS and alloy 52 compositions. This means that a given $\mathrm{Cr}$ content gives a corresponding dilution coefficient of LAS in alloy 52, which fixes the local composition. Injecting this information in eq. (3.3) yields the final relationship between $A(x)$ and $c_{C r}(x)$ :

$$
c_{C r}(x)=\frac{c_{C r}^{\text {al52 }}\left(A(x) \mu_{\text {above }}^{\text {steel }}-\mu_{\text {below }}^{\text {steel }}\right)-c_{C r}^{\text {steel }}\left(A(x) \mu_{\text {above }}^{\text {als2 }}-\mu_{\text {below }}^{\text {als2 }}\right)}{\left(A(x) \mu_{\text {above }}^{\text {steel }}-\mu_{\text {below }}^{\text {steel }}\right)-\left(A(x) \mu_{\text {above }}^{\text {al52 }}-\mu_{\text {below }}^{\text {al52 }}\right)}
$$

where $\mu^{\text {steel }}$ and $\mu^{a l 52}$ are the linear absorption coefficients calculated for the LAS and alloy 52 respectively, and $c_{C r}^{\text {steel }}$ and $c_{C r}^{a l 52}$ are their $\mathrm{Cr}$ contents respectively. Since transmission was measured at 6 energies below and 1 energy above the edge, eq. (4) was applied to obtain 6 estimations, the median of which was retained as the local composition. Once the local composition is known, the local thickness 
can be computed through eq. (2), and the intensity can then be normalized with respect to the local thickness.

The precipitates have been shown to be elongated, with a wide variety of sizes and orientations due to the variation of local composition and microstructure. Since these features must be captured with a single model, the precipitate signal was modeled using a "unified scattering" model [22] for elongated particles. In addition to that of the precipitates, the contribution of large-scale features giving rise to a Porod type intensity $\frac{k_{p}}{q^{n}}$ was also considered [23,24].

Figure 3 shows a few typical SAXS patterns obtained on the 50kh@350C sample across the fusion boundary, along with the corresponding model fits as solid lines. The fit is satisfactory given the variation in matrix composition and precipitate morphology and $\chi^{2}$ values were systematically smaller than 1.

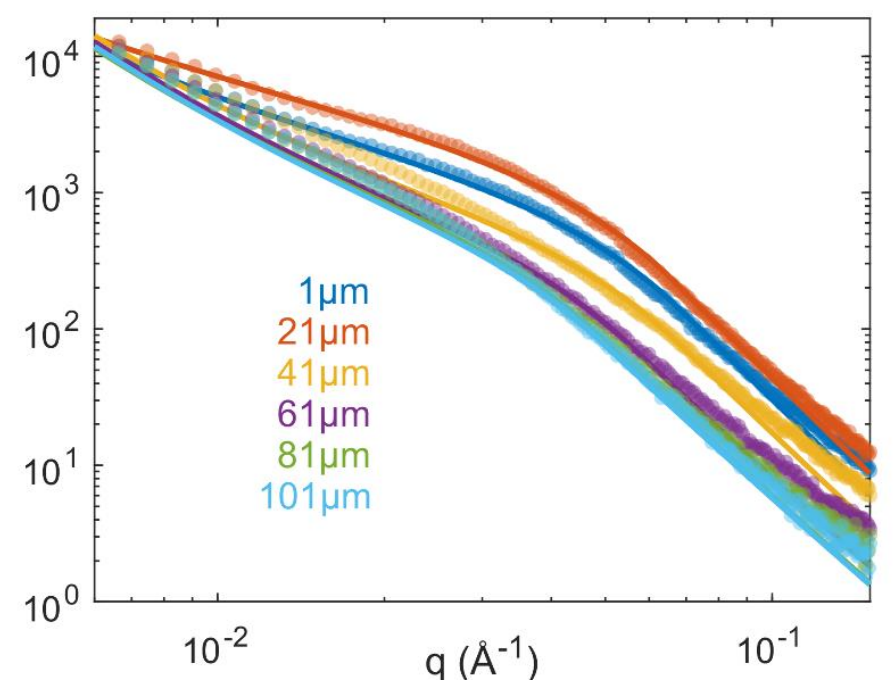

Figure 3: Selected small angle $X$-ray scattering patterns in weld at different distances from the fusion boundary for the 50kh@350C sample. Experimental data (circles) and corresponding model fits (solid lines).

The primary output of the fit is the integrated intensity, from which the precipitate volume fraction $f_{v}$ can be computed:

$$
Q_{0}=\int_{0}^{\infty} I_{\text {precip }}(q) q^{2} d q=2 \pi^{2}(\Delta \rho)^{2} f_{v}\left(1-f_{v}\right)
$$

where $q$ is the scattering vector defined as $q=\frac{4 \pi}{\lambda} \sin \theta, \lambda$ is the wavelength, $2 \theta$ is the scattering angle and $\Delta \rho$ is the difference in the electron density between matrix and the precipitates [25]:

$$
\Delta \rho=\sum_{i} \frac{f_{i} X_{p}^{i}}{\Omega_{p}}-\sum_{i} \frac{f_{i} X_{m}^{i}}{\Omega_{m}}
$$

where $f_{i}$ is the scattering factor, $X_{p}^{i}$ and $X_{m}^{i}$ are the individual atomic fractions of each species $i$ in the precipitates and the matrix, respectively. $\Omega_{p}$ and $\Omega_{m}$ are the average atomic volume of the precipitates and the matrix, respectively. For the precipitates, it will be discussed further in the paper that they are assumed to be mostly $\mathrm{Cr}_{23} \mathrm{C}_{6}$ carbides. In the literature, $\mathrm{Cr}_{23} \mathrm{C}_{6}$ lattice parameter is reported to range from $10.631 \AA$ [26] to $10.660 \AA$ [27]. A reasonable, approximate value of $10.65 \AA$ was used, leading to an atomic volume $\Omega_{p}$ of $10.413 \AA^{3}$. 
For the matrix, the aforementioned assumption of a simple rule of mixtures was kept, whereby the local composition and atomic volume are considered to be weighted averages of the properties of the LAS and alloy 52. This leads to a continuous variation of the matrix atomic volume $\Omega_{m}$ ranging between $11.777 \AA^{3}$ (LAS) and 11.471 $\AA^{3}$ (alloy 52). While the simple mixture assumption is an approximation for the atomic volume, the influence of a different value will be of minute influence given the ratio between $\Omega_{m}$ and $\Omega_{p}$.

\section{Results}

\section{A. Near fusion boundary microstructure}

Figure 4a shows a macrograph of the cross section of the DMW mockup between 18MND5 and Z2CND18-12, with alloy 52 as filler metal. The heat affected zone (HAZ) from welding can be observed. Figure $4 \mathrm{~b}$ shows a higher magnification optical micrograph of the same weld at the LAS fusion boundary. Given the size of the HAZ seen in Figure 4a, the LAS part shown in b is entirely in the HAZ. A "white" layer with a thickness ranging from about 10 to $20 \mu \mathrm{m}$ is observed next to the fusion boundary. This zone, where no microstructural features can be distinguished, results from local solidification conditions that lead to plane front growth [28]. Further away from the fusion boundary, it is replaced by a dendritic microstructure where carbide precipitation appears as a dark layer.
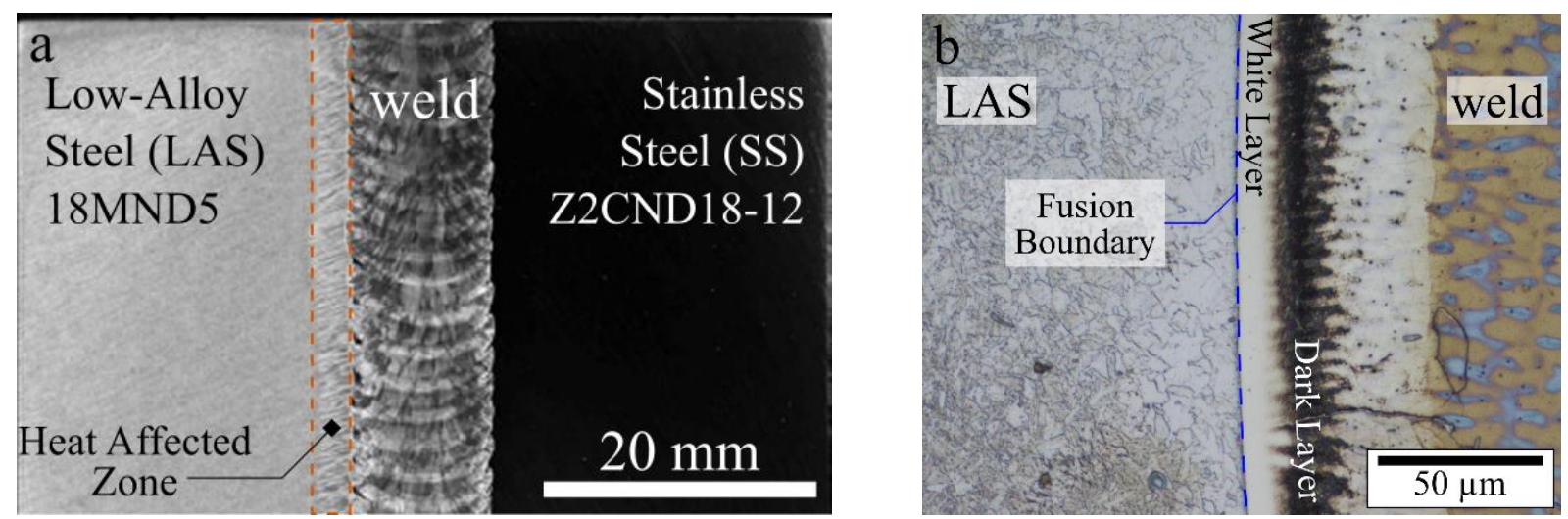

Figure 4. (a) Macrograph of the DMW mockup. (b) Micrograph of the 18MND5 low-alloy steel fusion boundary. Characteristic microstructural features are highlighted including the "white" and "dark" layers on the weld side, manifestations of the local composition gradient.

\section{B. Composition profiles across the boundary}

EPMA results yield composition profiles with a micron scale resolution across the boundary for the main substitutional elements ( $\mathrm{Cr}, \mathrm{Mn}, \mathrm{Fe}$ and $\mathrm{Ni}$ ) and carbon. The weld investigated here presents typical features of a DMW with filler metal. Right at the fusion boundary, the substitutional element compositions start evolving from the LAS to the weld metal composition, which results from the dilution of molten LAS into the filler metal. This transition occurs in the partially mixed zone (PMZ), over about $50 \mu \mathrm{m}$ as shown in Figure 5. A carbon build-up can be seen on the weld side of the fusion boundary in all the samples studied here. Its extent and peak value varies as a function of thermal aging conditions. On the LAS side, there exists a carbon-depleted zone [1,2], whose gradient indicates a transfer of carbon from the LAS to the weld. 

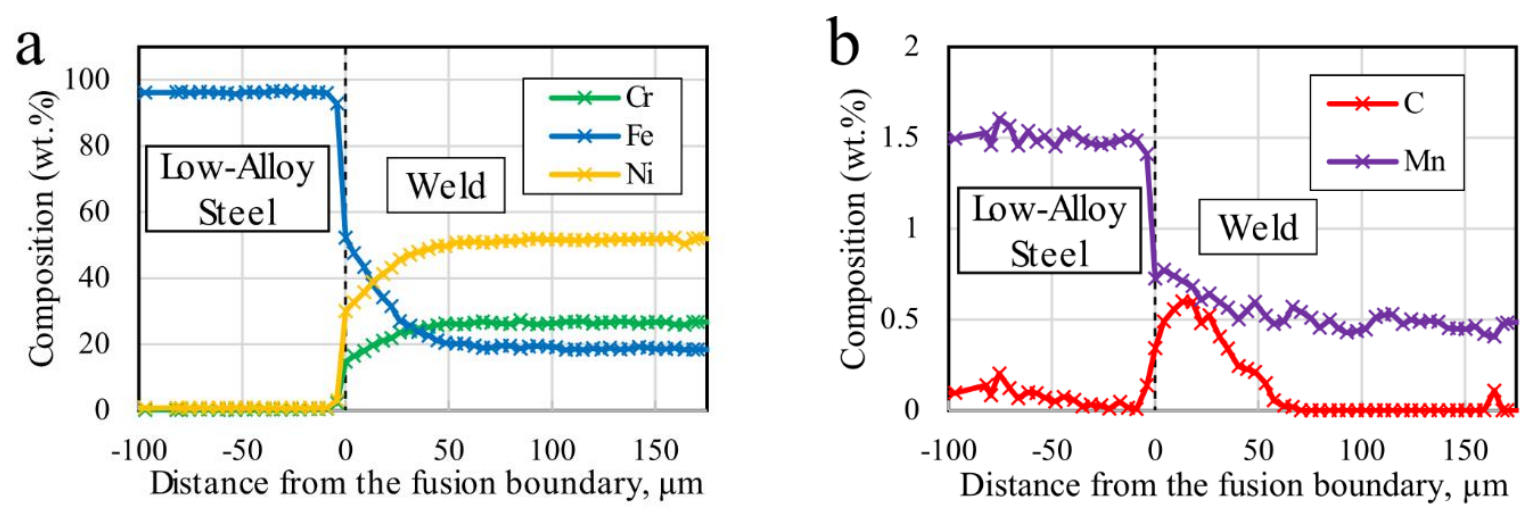

Figure 5. Composition profiles measured by EPMA, perpendicularly across the fusion boundary (steel on the left and weld on the right) in sample 5kh@450C: (a) $\mathrm{Cr}$, Fe, Ni profiles, (b) $\mathrm{C}$ and Mn profiles

Given the monotonic evolution of substitutional element compositions, the local composition can be used to confirm or refine the position of SAXS and atom probe data points in the profile. The chromium composition profile derived from the absorption profile recorded simultaneously with the SAXS patterns allows refining their position with respect to the fusion boundary. The agreement between the composition profiles from X-ray absorption, atom probe and EPMA is excellent as can be seen in Figure 6. The micrographs of the ROIs where the measurements were performed can be seen in Supplementary Figure 1.

Chromium contents measured using X-ray transmission around the chromium $\mathrm{K}$ absorption edge are slightly overestimated in the weld. This could be due to the simple assumption that the complete local composition can be derived from the local chromium content as detailed in II.F. It could also be related to a variation of the lattice parameter of the austenite matrix phase along the composition gradient, which could not be accounted for here.

It can be seen that local carbon content from atom probe data is also generally in good agreement with EPMA results. This suggests that the carbon underestimation due to multiple hits leading to detector pile-up, which is commonly seen in the analyses of carbide phases [29], did not significantly affect the present measurements. Certain carbon concentration points from AP lie noticeably higher than the corresponding value from EPMA. This is related to the size of the typical volumes investigated here by atom probe (of the order of $10^{-4} \mu \mathrm{m}^{3}$ ) through two possibly simultaneous effects. First, they are much smaller than the volume probed by EPMA (of the order of $1 \mu \mathrm{m}^{3}$ ), whose convolution with the "true" carbon concentration profile leads to a lower value of the build-up peak content. Second, the carbon content of the atom probe volumes is highly dependent on the number of intercepted carbides.

Atom probe analyses provide the opportunity to isolate the matrix from secondary phases and assess its local composition. To this end, precipitates are delimitated using a carbon isoconcentration surface at 5 at.\%. This method is both sensitive and specific given the large concentration difference between the potential carbides (20 - 50 at.\%) and the solid solution whose concentration is necessarily lower than the maximum local overall content $(\approx 5$ at. $\%)$. They are then removed from the analyzed volume from which the matrix composition can be calculated. 
a) PWHT

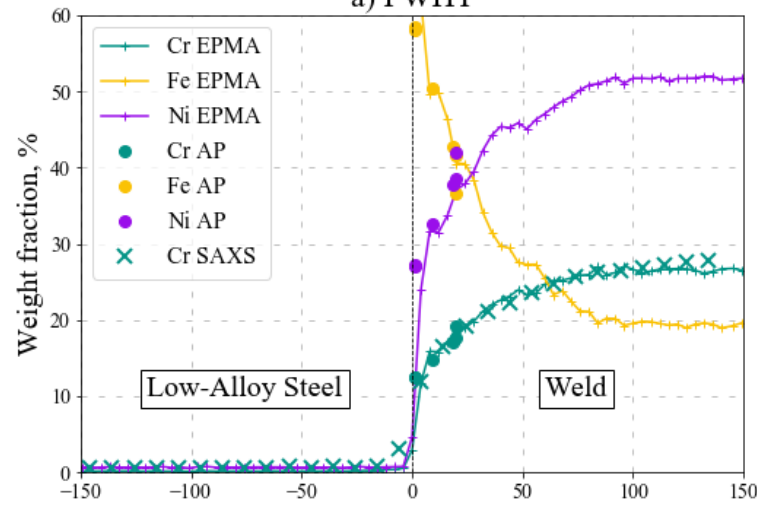

b) $\mathrm{PWHT}+450^{\circ} \mathrm{C}, 5000 \mathrm{~h}$

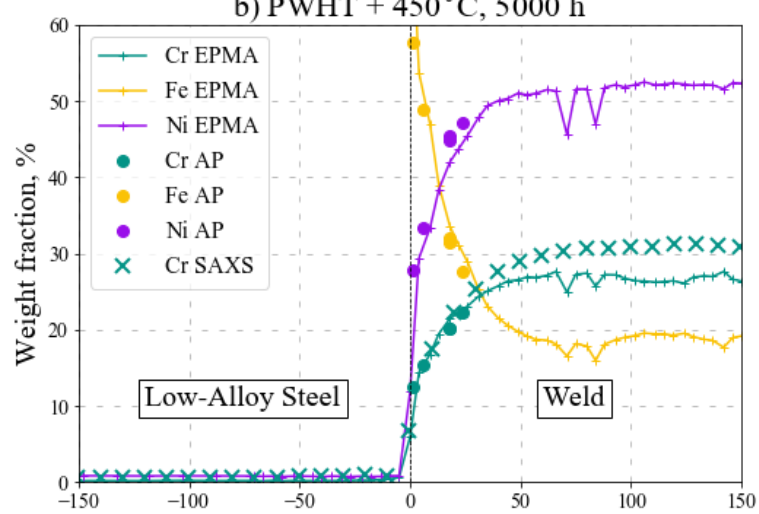

c) $\mathrm{PWHT}+350^{\circ} \mathrm{C}, 50000 \mathrm{~h}$

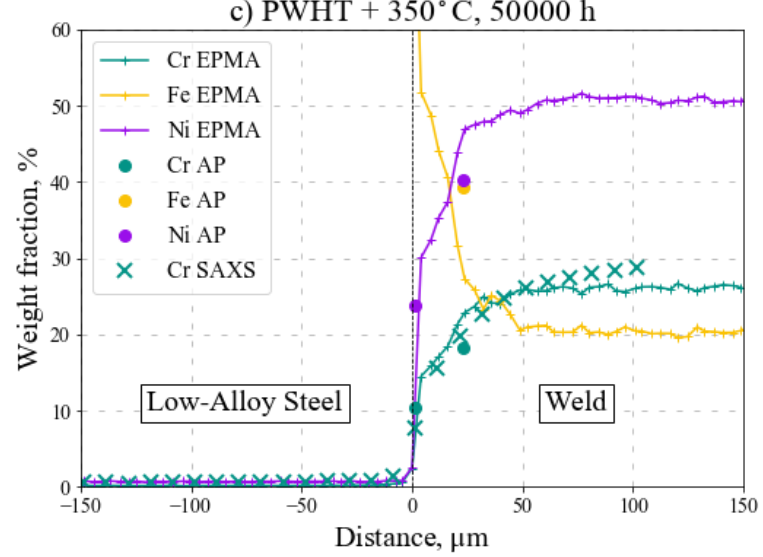

d) PWHT

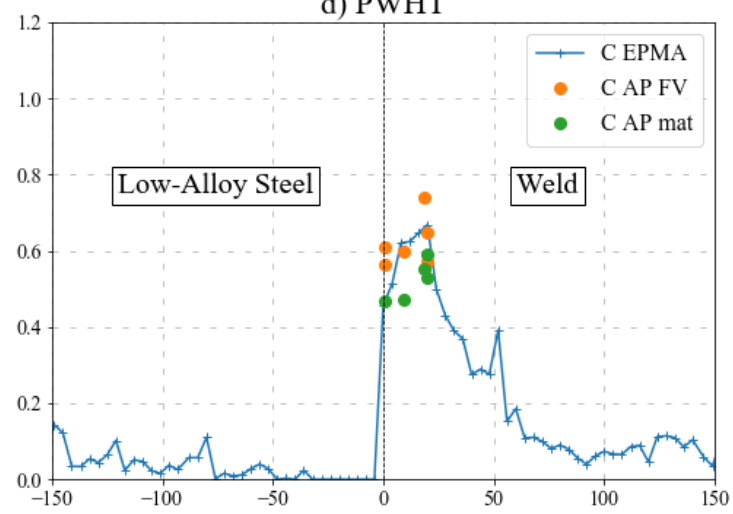

e) $\mathrm{PWHT}+450^{\circ} \mathrm{C}, 5000 \mathrm{~h}$

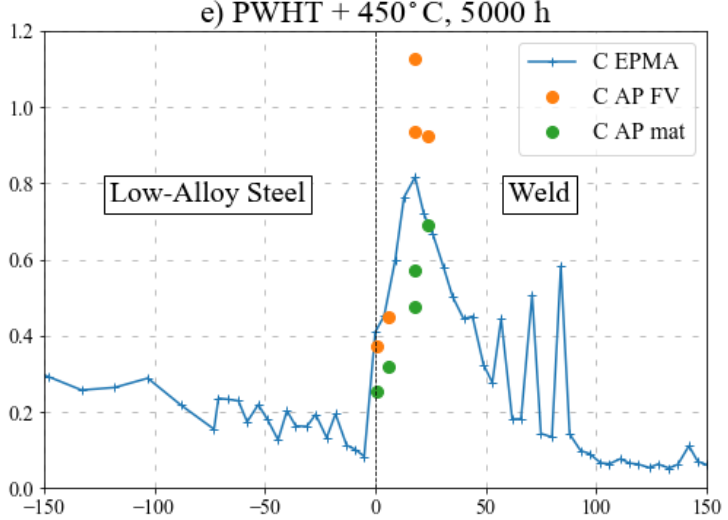

f) $\mathrm{PWHT}+350^{\circ} \mathrm{C}, 50000 \mathrm{~h}$

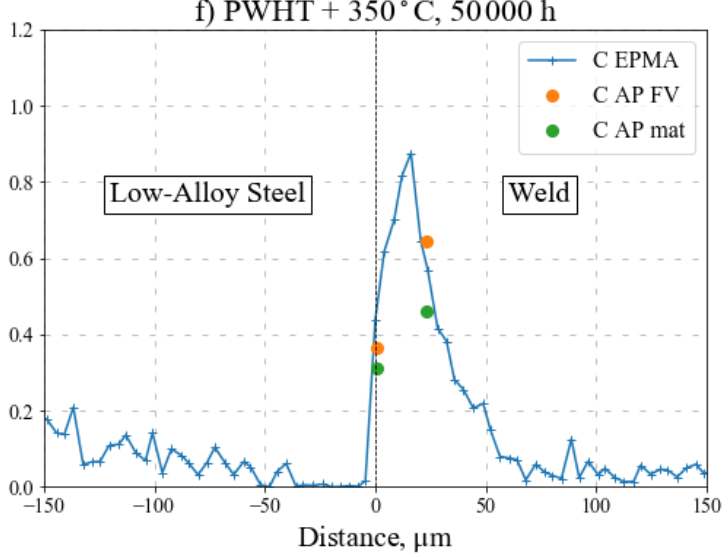

Figure 6: Spatially-resolved composition information from electron probe micro-analyses, atom probe and $X$-ray absorption, perpendicularly across the fusion boundary (steel on the left, weld on the right) for the main substitutional elements in samples a) PWHT, b) $5 \mathrm{kh} @ 450 \mathrm{C}$ and c) 50kh @350C and for carbon in samples d) PWHT, e) $5 \mathrm{kh} @ 450 \mathrm{C}$ and f) $50 \mathrm{kh} @ 350 \mathrm{C}$. Atom probe data allow the measurement of carbon content for either the full analyzed volume (FV) or the solid-solution matrix (mat).

\section{Precipitation in the weld near the fusion boundary}

Carbide precipitates can be observed in the majority of the atom probe tomograms reconstructed in this study, as shown in Figure 7. As indicated above, these carbides can be identified and isolated from the matrix given their large carbon composition difference with the matrix. The measured carbon contents for the individual objects vary from 18 to 32 at.\%. Looking closer at the composition of those individual carbide precipitates, they can be sorted in two categories: the majority ones with high $\mathrm{Cr}$ content (> 50 at.\%) and those that are scarcer with high Ti content (> 40 at.\%), as shown in Figure 8. 

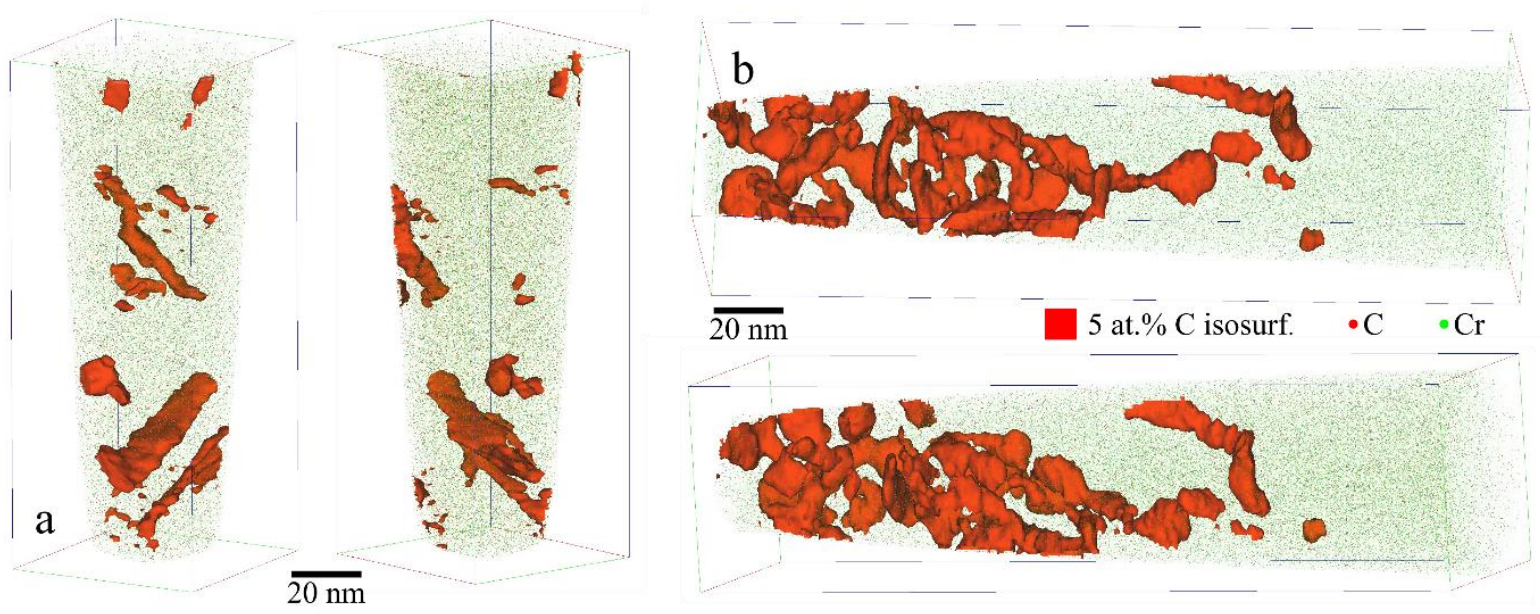

Figure 7: Tomograms of atom probe specimens taken from samples a) PWHT and b) 5kh@450C, $1 \mu \mathrm{m}$ and $6 \mu \mathrm{m}$ away from their respective fusion boundaries. They show all recorded $\mathrm{C}$ atoms (red dots) and $10 \%$ of recorded $\mathrm{Cr}$ atoms (green dots). The 5 at.\% $\mathrm{C}$ isoconcentration surface that was used to separate carbides from the matrix is also shown in red.
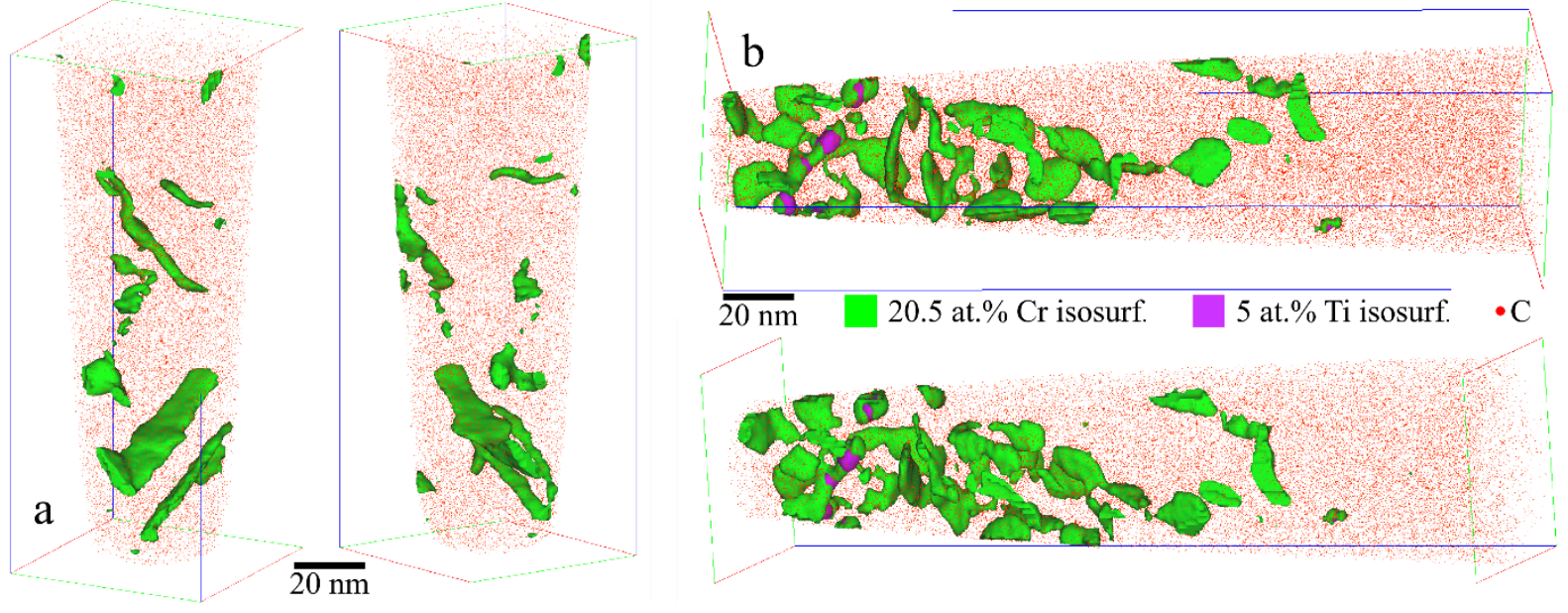

Figure 8: Tomograms of atom probe specimens taken from samples a) PWHT and b) 5kh@450C, $1 \mu \mathrm{m}$ and $6 \mu \mathrm{m}$ away from their respective fusion boundaries, same as Figure 7 . They show all recorded $\mathrm{C}$ atoms (red dots. The $\mathrm{Cr}$ and $\mathrm{Ti}$ isoconcentration surfaces reveal that the majority of carbides are chromium-rich. Some titanium-rich carbides can be found but are much scarcer, sometimes completely absent from the analyzed volume, such as the one shown in a).

Local equilibrium volume fractions of precipitates were calculated with the Thermo-Calc 2020a software package and database TCFE9 using data from both atom probe and EPMA in order to assess the uncertainty introduced by the measurement artefacts discussed above. It can be seen in Figure 9 that the total equilibrium fractions are closely similar for both concentration values but the equilibrium phases can change. The presence of $\mathrm{M}_{23} \mathrm{C}_{6}\left(\mathrm{M}=\right.$ metallic atom) is predicted at all locations. $\mathrm{M}_{7} \mathrm{C}_{3}$ is predicted for composition points where carbon and/or iron contents are elevated but even then, $\mathrm{M}_{23} \mathrm{C}_{6}$ is still the most abundant carbide. Reports from the literature concerning 18MND5 ( $\approx$ SA508 Gr.3)/ alloy 52 DMWs mention mostly chromium rich $\mathrm{M}_{23} \mathrm{C}_{6}$ precipitates on the weld side of the ferrite / austenite fusion boundary. In particular, it was noted that the high chromium content found in alloy 690, which is closely similar to alloy 52, destabilizes $\mathrm{M}_{7} \mathrm{C}_{3}$ in favor of $\mathrm{M}_{23} \mathrm{C}_{6}[30]$. 
Volume fractions calculated with $\mathrm{C}$ content from AP
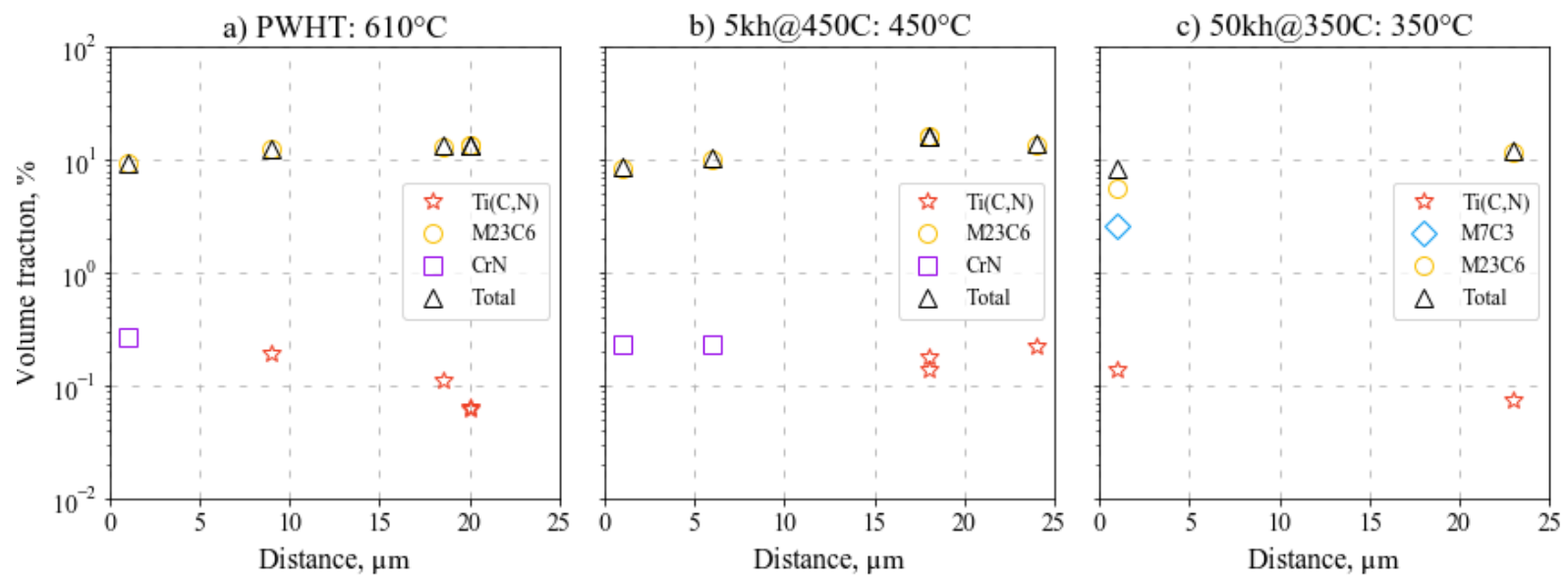

Volume fractions calculated with C content from EPMA
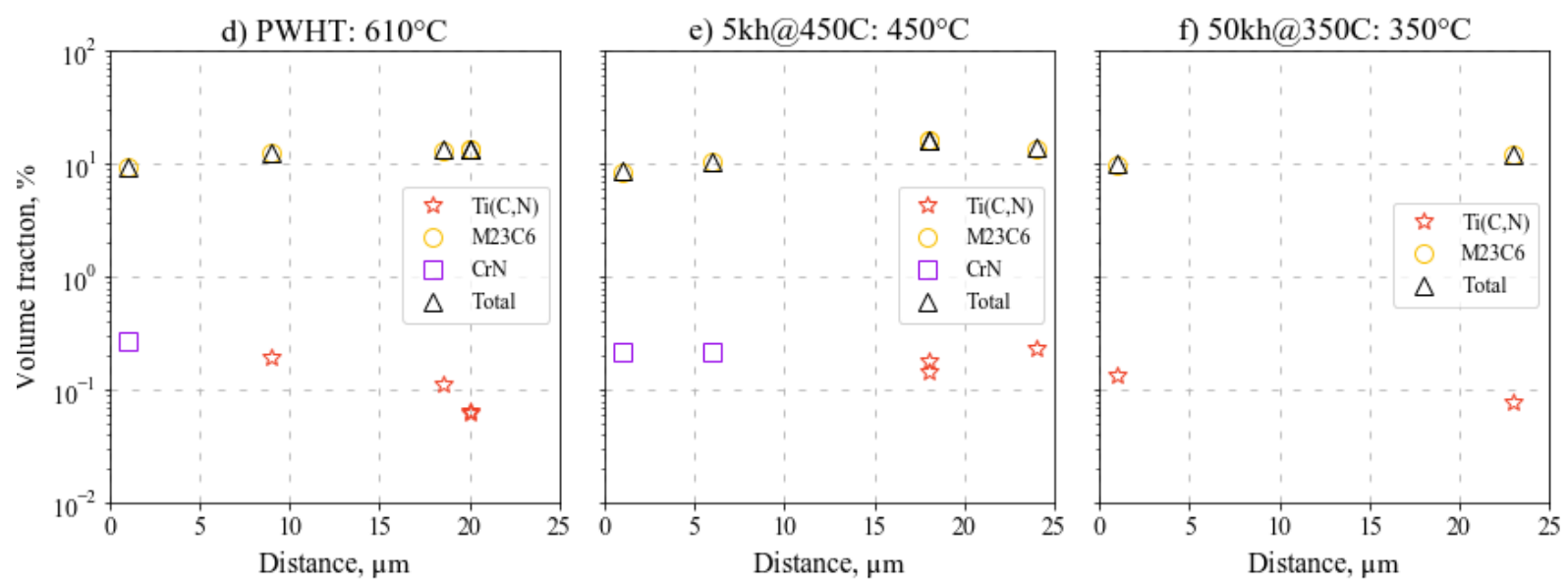

Figure 9 : Volume fraction of precipitates at equilibrium in the austenitic matrix calculated by Thermo-Calc in samples a) PWHT at $610^{\circ} \mathrm{C}$, b) $5 \mathrm{kh} @ 450 \mathrm{C}$ at $450^{\circ} \mathrm{C}$ and c) $50 \mathrm{kh} @ 350 \mathrm{C}$ at $350^{\circ} \mathrm{C}$ based on compositions measured by atom probe. Calculations were run at the same temperatures with carbon content changed to values measured by EPMA for d) PWHT, e) 5kh@450C and f) 50kh@350C. It should be noted that the plots are semi-logarithmic to better show low-fraction phases.

The calculations also predict the presence of $\mathrm{CrN}$ chromium nitrides or $\operatorname{Ti}(\mathrm{C}, \mathrm{N})$ titanium carbo-nitrides in small amounts depending on the local chromium and/or nitrogen content. No precipitate consistent with $\mathrm{CrN}$ was observed in the atom probe data but $\operatorname{Ti}(\mathrm{C}, \mathrm{N})$ corresponds well to the titanium rich precipitates that were found.

The expected fraction of $\mathrm{M}_{23} \mathrm{C}_{6}$ is always 10 to 100 times that of other potential secondary phases, as shown in Figure 9. Additionally, it is the only precipitate phase whose presence could be shown experimentally [2]. Consequently, all precipitates will be considered as $\mathrm{M}_{23} \mathrm{C}_{6}$ only for the remaining of the study. The metallic atoms in those carbides are mostly chromium but they can contain a nonnegligible amount of iron as shown in Figure 10. 

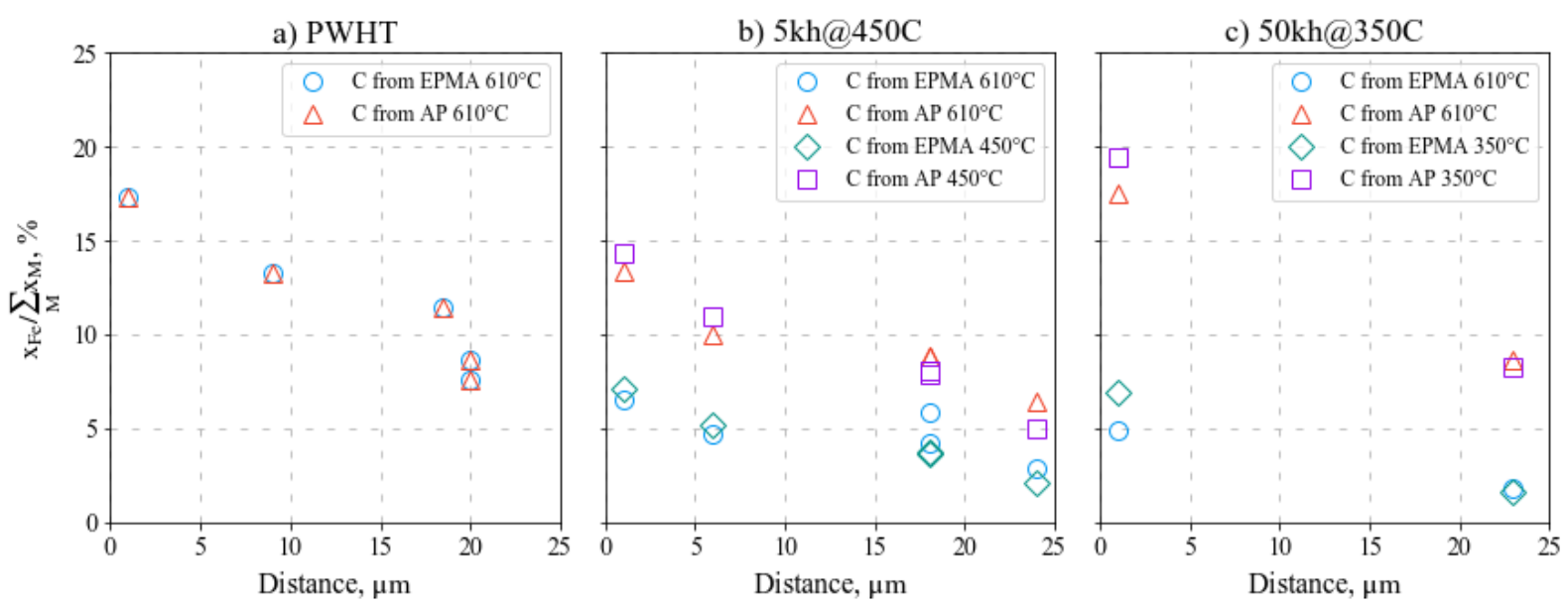

Figure 10: Equilibrium iron fraction in the metallic sites of $M_{23} C_{6}$ in samples a) PWHT, b) 5kh@450C and c) 50kh@350C as calculated by Thermo-Calc software package, using carbon contents given by either electron probe micro-analysis (EPMA) or atom probe (AP).

The largest iron content in $\mathrm{M}_{23} \mathrm{C}_{6}$ is always found closest to the fusion boundary where the overall iron content is the largest too. It is also larger at higher temperature with greater contents found at PWHT temperature than at the various aging temperatures. For the various data points considered here, it ranges from about 2 to $20 \%$ of metallic atom (M) sites in $\mathrm{M}_{23} \mathrm{C}_{6}$. In the following, where $\mathrm{M}_{23} \mathrm{C}_{6}$ iron content is required, this range will be considered.

\section{Quantification of carbide precipitation in the weld}

Spatially resolved SAXS measurements enabled to map the volume fraction of precipitates in the nearfusion boundary region of the weld as well as the chromium local composition as given by the local transmission of the sample. This has been shown on Figure 11. For these maps, it was assumed that iron made up for $10 \%$ the metallic atoms in $\mathrm{M}_{23} \mathrm{C}_{6}$. It can be observed that the calculated volume fraction is maximum close to the fusion boundary as confirmed by the chromium composition maps that show chromium composition rising close to this precipitate fraction maximum, found around 5-15 wt.\% Cr.

An alternative, independent estimation of the local precipitate volume fraction can be obtained through a mass balance based on the local overall composition, the local matrix composition and the precipitate composition. The precipitate composition is known, assuming $\mathrm{M}_{23} \mathrm{C}_{6}$ like for SAXS data analysis. Matrix carbon content is based on atom probe data and overall carbon content is taken from EPMA measurements to avoid artifacts due to the small size of atom probe analysis volumes. Fractions calculated like so can be compared to fractions obtained from SAXS data, as shown in Figure 12.

It can be seen in Figure 12a that in the case of sample PWHT, SAXS data suggest a monotonous decrease of the $\mathrm{M}_{23} \mathrm{C}_{6}$ volume fraction from the highest fraction, found directly after the fusion boundary, at around $2 \%$ to fractions below $0.5 \% 50 \mu \mathrm{m}$ into the weld metal. Fractions calculated from EPMA/APT carbon content suggest instead an increase from a low point close to the fusion boundary to a high value, around $4 \%, 9 \mu \mathrm{m}$ away. The fraction then slowly decreases until $20 \mu \mathrm{m}$ to around $3 \%$.

In Figure 12b, the SAXS data of sample 5kh@450C exhibits the same trend as that of sample PWHT, although its starting value is higher around $3 \%$. Atom probe results agree rather well with this starting point but suggest that there exists a maximum value of about $7 \%$ volume fraction $20 \mu$ m away from the boundary. The fraction then comes back down and is below $0.5 \%$ further than $50 \mu \mathrm{m}$ from the fusion boundary. 

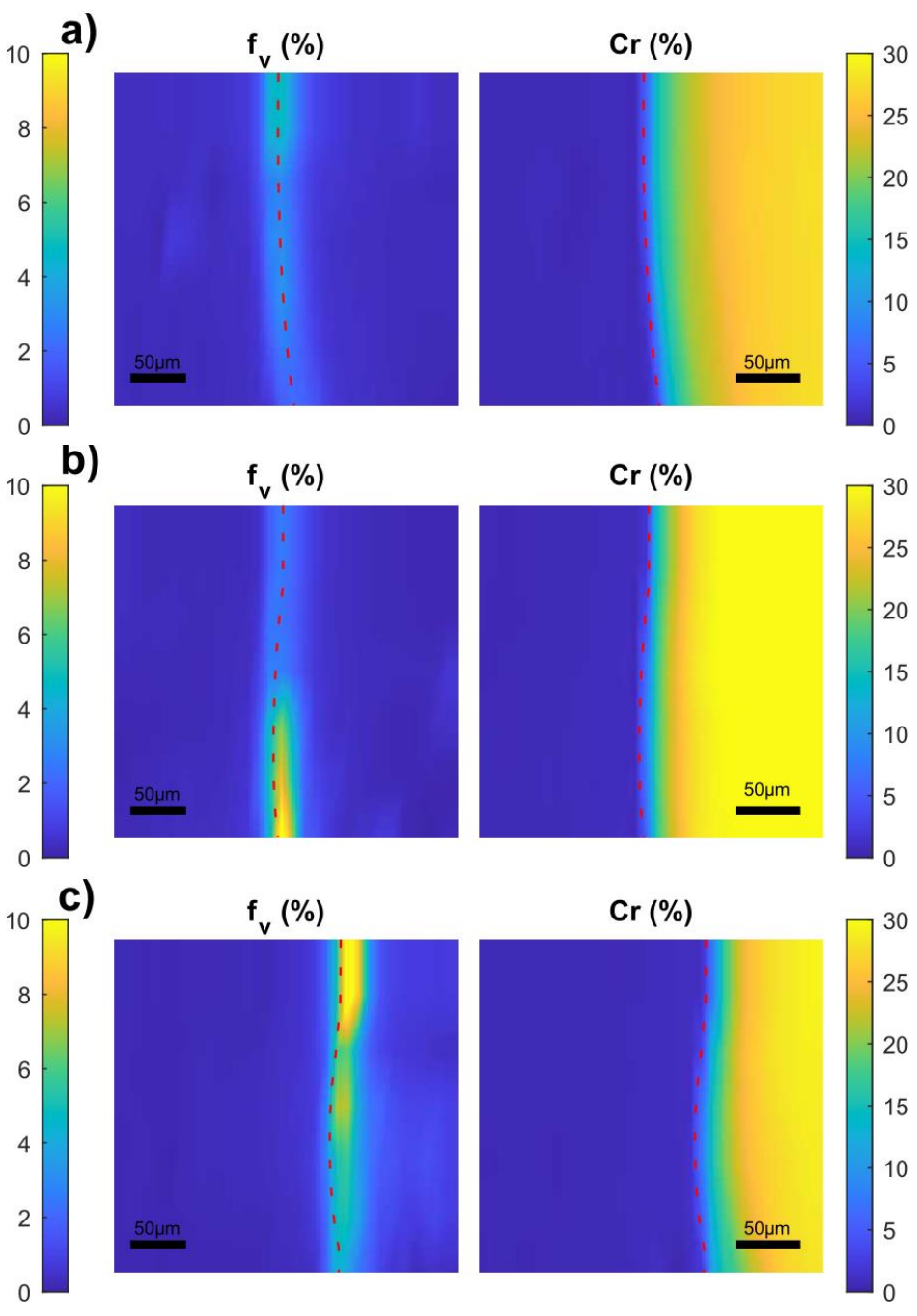

Figure 11: $\mathrm{M}_{23} \mathrm{C}_{6}$ volume fraction and chromium content maps (in wt.\%) calculated from $\mathrm{X}$-ray scattering data in samples a) PWHT, b) $5 \mathrm{kh} @ 450 \mathrm{C}$ and c) $50 \mathrm{kh} @ 350 \mathrm{C}$. The red dashed lines represent the $5 \mathrm{wt} . \% \mathrm{Cr}$ isocomposition line. The fusion boundary lies a few microns to the left of this line.
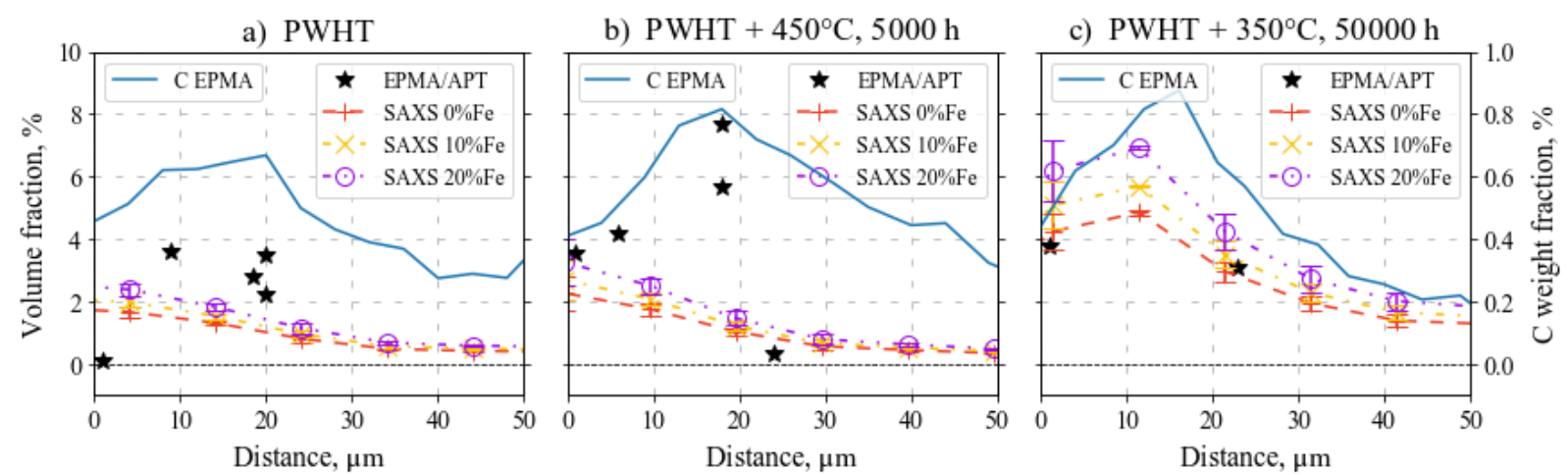

Figure $12: \mathrm{M}_{23} \mathrm{C}_{6}$ volume fractions calculated from local carbon mass balance compared with volume fractions derived from SAXS patterns in sample a) PWHT, b) 5kh@450C and c) 50kh@350C. Starshaped symbols indicate volume fractions based on local carbon contents, for which overall contents were measured by EPMA and matrix contents were measured by APT. Different iron concentrations in $\mathrm{M}_{23} \mathrm{C}_{6}$ were assumed in the SAXS analysis to assess the effect of this parameter on the resulting volume fraction. 
In Figure 12c, for sample 50kh@350C, SAXS data starts at a fraction of roughly $5 \%$ and increases to a maximum of about $6 \%$ at a distance of $10 \mu \mathrm{m}$ from the fusion boundary. It should be noted that the evolution of the carbide iron content, from iron rich to iron lean when moving away from the fusion boundary, could smooth out this maximum. Further, the volume fraction goes back down but remains above $1 \%$ within $50 \mu \mathrm{m}$ of the fusion boundary. The APT data is too sparse to reveal any trend but agrees well with the SAXS results where available.

\section{Discussion}

\section{A. Relevance of correlative characterization for DMWs}

DMWs are joints, in which the microstructure varies significantly and non-monotonously along the fusion boundaries. To tackle the problem of carbide precipitation due to carbon transport across the austenite/ferrite fusion boundary, it was necessary to obtain multiple kinds of information (overall chemical composition, matrix composition, precipitate fraction) that could only be acquired by using different characterization techniques and later combined during data processing. Given the microstructural inhomogeneity, this only makes sense if those measurements are carried out in the same ROI and the datasets can be positioned with great precision with respect to each other.

For APT analyses, this issue proved to be successfully overcome with FIB preparation of the atom probe specimens, during which the fusion boundary is directly visible on the etched sample. The compositions obtained by APT matched very well the ones recorded by EPMA at the targeted locations. For SAXS analyses, not being able to position the beam finely enough during recording was circumvented by measuring the local chromium composition using X-ray transmission measurements at a series of energies below and above the chromium edge. The obtained profiles proved to match well those obtained from EPMA and it was thus possible to reposition the data with a better precision than the EPMA profile step size $(4 \mu \mathrm{m})$. Thus, accurate spatial position of the data profiles is confirmed across all techniques. This enables reliable combination and comparison of the various data points.

\section{B. Agreement of precipitate quantifications}

It can be seen from Figure 12 that precipitate quantification from SAXS and composition measurements yield values in a comparable range, between 0 and $7 \%$ in the PMZ. The local agreement between the two techniques is, however, not perfect. The observed discrepancy may have different origins.

One possible explanation is the difficulty in obtaining exploitable SAXS patterns at the same energy, free from multiple diffraction streaks. These streaks were particularly prominent on the weld side of the DMW due to the large grain size. Austenite grains in the weld are elongated in the solidification direction, perpendicular to the fusion boundary. They are several hundreds of microns wide and several millimeters long [2]. Given the present beam size and the thickness of the foil specimens, it means that most patterns in the weld corresponded to single-crystal matrix conditions leading to potential multiple diffraction events. Multiple diffraction in an imperfect single crystal causes streaks around the transmitted beam, overlapping with the SAXS signal of the precipitates and rendering patterns unusable. While the redundancy of measurements at six energies made it possible to exclude heavily streaked patterns, those that have been used may still be affected to some extent by multiple diffraction, which hinders their quantitativity.

Another possible explanation is the difference in probed volume. In the present experimental conditions, SAXS patterns originate from a volume around $10 \times 50 \times 30 \mu \mathrm{m}^{3}$ while typical APT datasets 
represented about $60 \times 60 \times 200 \mathrm{~nm}^{3}, 2 \times 10^{7}$ finer. This enables atom probe to capture local variations that end up being averaged in the SAXS measurements. Such local variations are especially pronounced past the white layer, in the cellular growth region where segregation from solidification causes precipitation inhomogeneity along the fusion boundary, as can be seen in Figure 4b. This larger probe size also makes SAXS measurements more sensitive to the non-planarity of the fusion boundary, even more so that it is elongated parallel to the fusion boundary. This also tends to smooth out the precipitate fraction profile.

\section{Evolution of carbide precipitates in 18MND5/ Alloy 52 DMWs}

Atom probe analyses indicate the presence of chromium rich and titanium rich carbide precipitates. Comparison with results from the literature or thermodynamic calculations shown in Figure 9 suggests that the former are $\mathrm{M}_{23} \mathrm{C}_{6}$ carbides and the latter are $\mathrm{Ti}(\mathrm{C}, \mathrm{N})$ carbonitrides. Atom probe data and simulations show that $\mathrm{M}_{23} \mathrm{C}_{6}$ constitute the most abundant precipitates across the whole PMZ. After PWHT, the maximum local precipitate volume fraction was recorded at about $4 \%$ and the majority of the precipitates seem to be located within the first $20 \mu \mathrm{m}$ past the boundary. After $5000 \mathrm{~h}$ of aging at $450^{\circ} \mathrm{C}$, the majority of precipitates are still located in the same region but the peak local volume fraction could be as high as about $8 \%$. After $50000 \mathrm{~h}$ at $350^{\circ} \mathrm{C}$, carbide precipitation has progressed further in the weld, even though the depth in the weld affected by long-range carbon redistribution did not change significantly. Data is insufficient to determine the maximum local fraction but SAXS results suggest it might be higher than after $5000 \mathrm{~h}$ at $450^{\circ} \mathrm{C}$. In all cases, the fractions obtained experimentally are all far below equilibrium values predicted by thermodynamic calculations. This suggests that precipitation kinetics cannot be considered "infinitely" fast in models of microstructural evolutions of the DMWs, whether during PWHT or in service aging. The data collected here provides an estimate of the precipitate volume fraction profile and its evolution during aging that could be compared to precipitation kinetics simulations results.

\section{Conclusion}

SAXS and APT in conjunction with EPMA were used to investigate precipitation in the near-fusion boundary region of an 18MND5/alloy 52 DMW after PWHT and simulated in-service aging. Data sets from all techniques could be precisely positioned with respect to each other by using the chromium composition profile. Atom probe analyses showed that $\mathrm{M}_{23} \mathrm{C}_{6}$ carbides were the most abundant secondary phase, but also evidenced the presence of other precipitates such as $\operatorname{Ti}(\mathrm{C}, \mathrm{N})$.

Carbon contents and SAXS patterns were successfully used to calculate profiles of local precipitate volume fraction. The fraction profiles obtained by both methods, while in reasonable agreement, showed some differences. This discrepancy is thought to be mostly due to the large difference between the volumes probed in atom probe and SAXS, combined with the pronounced inhomogeneity of the microstructure along the fusion boundary. Both techniques showed the same trends sample to sample:

- Precipitation is more abundant in all aged samples than in the PWHT sample.

- After aging for $5000 \mathrm{~h}$ at $450^{\circ} \mathrm{C}$, the additional precipitates form within $20 \mu \mathrm{m}$ past the fusion boundary, in the same region where precipitates were located after PWHT.

- Aging for $50000 \mathrm{~h}$ at $350^{\circ} \mathrm{C}$ results in even more precipitates that can form as far as $50 \mu \mathrm{m}$ from the fusion boundary.

- In all cases, local volume fractions are well below the local equilibrium fractions predicted by thermodynamic calculations. 
These results indicate that the precipitation kinetics should be accounted for to accurately model the microstructural evolution of these DMWs, in particular carbon transport, during either PWHT or operation, which is a necessary step towards reliable modeling of the evolution of their mechanical properties. The data reported here can be used for comparison with the results of such precipitation models.

\section{Acknowledgement}

We acknowledge the Paul Scherrer Institut, Villigen, Switzerland for the provision of synchrotron radiation beamtime at beamline X12SA cSAXS of the SLS. We would especially like to thank Dr. A. Menzel for assistance.

APT experiments were carried out thanks to the GENESIS experimental platform. GENESIS is supported by the Région Haute Normandie, the Métropole Rouen-Normandie, the CNRS via LABEX ERC, and the ANR as part of the program "Investissements d'Avenir", under reference ANR-11-EQPX0020 .

\section{Data availability}

The raw and processed data required to reproduce these findings cannot be shared at this time as the data also forms part of an ongoing study.

\section{Declaration of interest}

The authors declare the following financial interests/personal relationships, which may be considered as potential competing interests: M. Yescas and F. Roch are employees of Framatome. H.P. Van Landeghem and C. Tassin received research funds from Framatome, which were notably used to pay for the post-doctoral position of A. Akhatova.

\section{References}

[1] P. Joly, M. Yescas, E. Keim, Fracture Toughness in the Ductile-Brittle Transition and Thermal Ageing Behavior of Decarburized Heat Affected Zone of Alloy 52 Dissimilar Metal Welds of Nuclear Components, in: Vol. 6A Mater. Fabr., ASME, Anaheim, California, USA, 2014. https://doi.org/10.1115/PVP2014-29044.

[2] A. Akhatova, F. Robaut, M. Verdier, M. Yescas, F. Roch, C. Tassin, H.P. Van Landeghem, Microstructural and mechanical investigation of the near fusion boundary region in thermally aged 18MND5 / alloy 52 narrow-gap dissimilar metal weld, Mater. Sci. Eng. A. 788 (2020) 139592. https://doi.org/10.1016/j.msea.2020.139592.

[3] J.N. DuPont, Microstructural evolution and high temperature failure of ferritic to austenitic dissimilar welds, Int. Mater. Rev. $57 \quad$ (2012) 208-234. https://doi.org/10.1179/1743280412Y.0000000006.

[4] M.L. Huang, L. Wang, Carbon migration in $5 \mathrm{Cr}-0.5 \mathrm{Mo} / 21 \mathrm{Cr}-12 \mathrm{Ni}$ dissimilar metal welds, Metall. Mater. Trans. A. 29 (1998) 3037-3046. https://doi.org/10.1007/s11661-998-0211-1.

[5] Z.R. Chen, Y.H. Lu, X.F. Ding, T. Shoji, Microstructural and hardness investigations on a dissimilar metal weld between low alloy steel and Alloy 82 weld metal, Mater. Charact. 121 (2016) 166-174. https://doi.org/10.1016/j.matchar.2016.09.033.

[6] K.J. Choi, S.C. Yoo, T. Kim, C.B. Bahn, J.H. Kim, Effects of aging temperature on microstructural evolution at dissimilar metal weld interfaces, J. Nucl. Mater. 462 (2015) 54-63. https://doi.org/10.1016/j.jnucmat.2015.03.044. 
[7] T. Sarikka, M. Ahonen, R. Mouginot, P. Nevasmaa, P. Karjalainen-Roikonen, U. Ehrnstén, H. Hänninen, Effect of mechanical mismatch on fracture mechanical behavior of SA 508 - Alloy 52 narrow gap dissimilar metal weld, Int. J. Press. Vessels Pip. 157 (2017) 30-42. https://doi.org/10.1016/j.ijpvp.2017.08.003.

[8] B.A. Soares, CHARACTERIZATION OF THE DISSIMILAR WELDING - AUSTENITIC STAINLESS STEEL WITH FILLER METAL OF THE NICKEL ALLOY, (2007) 6.

[9] VTT Technology 333: Thermal ageing and mechanical performance of narrow-gap dissimilar metal welds, (n.d.) 193.

[10] W. Wang, Y. Lu, X. Ding, T. Shoji, Microstructures and microhardness at fusion boundary of 316 stainless steel/Inconel 182 dissimilar welding, Mater. Charact. 107 (2015) 255-261. https://doi.org/10.1016/j.matchar.2015.07.018.

[11] H. Ming, J. Wang, E.-H. Han, Comparative study of microstructure and properties of low-alloysteel/nickel-based-alloy interfaces in dissimilar metal weld joints prepared by different GTAW methods, Mater. Charact. 139 (2018) 186-196. https://doi.org/10.1016/j.matchar.2018.02.044.

[12] J. Hou, Q.J. Peng, Y. Takeda, J. Kuniya, T. Shoji, J.Q. Wang, E.-H. Han, W. Ke, Microstructure and mechanical property of the fusion boundary region in an Alloy 182-low alloy steel dissimilar weld joint, J. Mater. Sci. 45 (2010) 5332-5338. https://doi.org/10.1007/s10853-010-4581-6.

[13] K.J. Choi, J.J. Kim, B.H. Lee, C.B. Bahn, J.H. Kim, Effects of thermal aging on microstructures of low alloy steel-Ni base alloy dissimilar metal weld interfaces, J. Nucl. Mater. 441 (2013) $493-$ 502. https://doi.org/10.1016/j.jnucmat.2013.07.003.

[14] K.J. Choi, T. Kim, S.C. Yoo, S. Kim, J.H. Lee, J.H. Kim, Fusion boundary precipitation in thermally aged dissimilar metal welds studied by atom probe tomography and nanoindentation, J. Nucl. Mater. 471 (2016) 8-16. https://doi.org/10.1016/j.jnucmat.2015.12.047.

[15] S. Wang, J. Ding, H. Ming, Z. Zhang, J. Wang, Characterization of low alloy ferritic steel-Ni base alloy dissimilar metal weld interface by SPM techniques, SEM/EDS, TEM/EDS and SVET, Mater. Charact. 100 (2015) 50-60. https://doi.org/10.1016/j.matchar.2014.12.007.

[16] A.L. Bowman, G.P. Arnold, E.K. Storms, N.G. Nereson, The crystal structure of Cr23C6, Acta Crystallogr. B. 28 (1972) 3102-3103. https://doi.org/10.1107/S0567740872007526.

[17] J. Ruste, Microanalyse X par sonde électronique - Principe et instrumentation, (2009) 23.

[18] J.L. Pouchou, F. Pichoir, Extension des possibilités quantitatives de la microanalyse par une formulation nouvelle des effets de matrice, J. Phys. Colloq. 45 (1984) C2-17-C2-20. https://doi.org/10.1051/jphyscol:1984204.

[19] F. Robaut, A. Crisci, M. Durand-Charre, D. Jouanne, Practical Aspects of Carbon Content Determination in Carburized Steels by EPMA, Microsc. Microanal. 12 (2006) 331-334. https://doi.org/10.1017/S1431927606060466.

[20] M.K. Miller, K.F. Russell, G.B. Thompson, Strategies for fabricating atom probe specimens with a dual beam FIB, Ultramicroscopy. 102 (2005) 287-298. https://doi.org/10.1016/j.ultramic.2004.10.011.

[21] F. Zhang, J. Ilavsky, G.G. Long, J.P.G. Quintana, A.J. Allen, P.R. Jemian, Glassy Carbon as an Absolute Intensity Calibration Standard for Small-Angle Scattering, Metall. Mater. Trans. A. 41 (2010) 1151-1158. https://doi.org/10.1007/s11661-009-9950-x.

[22] G. Beaucage, Approximations Leading to a Unified Exponential/Power-Law Approach to SmallAngle Scattering, J. Appl. Crystallogr. 28 (1995) 717-728. https://doi.org/10.1107/S0021889895005292.

[23] G. Porod, General Theory, in: O. Glatter, O. Kratky (Eds.), Small-Angle X-Ray Scatt., Academic Press, London, 1982: pp. 17-51.

[24] B. Hammouda, A new Guinier-Porod model, J. Appl. Crystallogr. 43 (2010) 716-719. https://doi.org/10.1107/S0021889810015773.

[25] A. Deschamps, F. de Geuser, Quantitative Characterization of Precipitate Microstructures in Metallic Alloys Using Small-Angle Scattering, Metall. Mater. Trans. A. 44 (2013) 77-86. https://doi.org/10.1007/s11661-012-1435-7.

[26] A.M. Casias, Influence of composition on precipitation behavior and stress rupture properties in INCONEL RTM740 series superalloys, PhD Thesis. (2013). http://adsabs.harvard.edu/abs/2013PhDT........13C (accessed April 11, 2019). 
[27] H.L. Yakel, Atom distributions in tau-carbide phases: Fe and $\mathrm{Cr}$ distributions in (Cr23-xFex)C6 with $\mathrm{x}=0,0.74,1 \cdot 70,4 \cdot 13$ and 7.36, Acta Crystallogr. B. 43 (1987) 230-238. https://doi.org/10.1107/S0108768187097957.

[28] F. Mas, C. Tassin, F. Roch, M. Yescas, P. Todeschini, Y. Bréchet, Growth Morphologies and Primary Solidification Modes in a Dissimilar Weld between a Low-Alloy Steel and an Austenitic Stainless Steel, Metals. 8 (2018) 284. https://doi.org/10.3390/met8040284.

[29] M. Thuvander, D. Shinde, A. Rehan, S. Ejnermark, K. Stiller, Improving Compositional Accuracy in APT Analysis of Carbides Using a Decreased Detection Efficiency, Microsc. Microanal. 25 (2019) 454-461. https://doi.org/10.1017/S1431927619000424.

[30] M. Roman, Effect of thermal ageing on Alloys 690 and 52 in pressurized water reactor applications, Aalto University, 2017. 